\title{
The Effects of Fertilizer Application on Soil Moisture, Groundwater, and Surface Water
}

\section{Erin Siebert, Alfred University}

Advisor: Michele Hluchy, Environmental Studies and Geology Division

\section{Background}

Nitrates and phosphates, particularly from fertilizers, make their way into systems, blooms of algae occur that When thesy neprete oxygen in the water, resulting in vast "dead zones" that are low in oxygen and acidic (Galloway et al. 2003). Anaerobic bacteria are the only organisms that can survive in these types of condlions which causes huge problems and decreases the

Sulfur is an important micro nutrient for plant growth and crop production. the sulfur foundial for chlorophyll formation and the synthesis of oils. Most of sulfur into a sulfate form that is readily available to plants through a process known as mineralization (Kivi and Bailey 2017). However if sulfate concentrations in the soil are too high then the soil moisture and groundwater can increase in sallity. An increase in sallity can hinder crop for many fish fungi, and microbes (Meiling et al. 2016).

The objective of this study was to determine if nitrate, phosphate, and sulfate from fertilizer move into and through the soil in an agricultura field and appear in the nearby stream water. This study specifically nearby stream water. The study took place in an agricultural field and small creek in a large ravine along Reed Hill Rd in Campbell, New York.

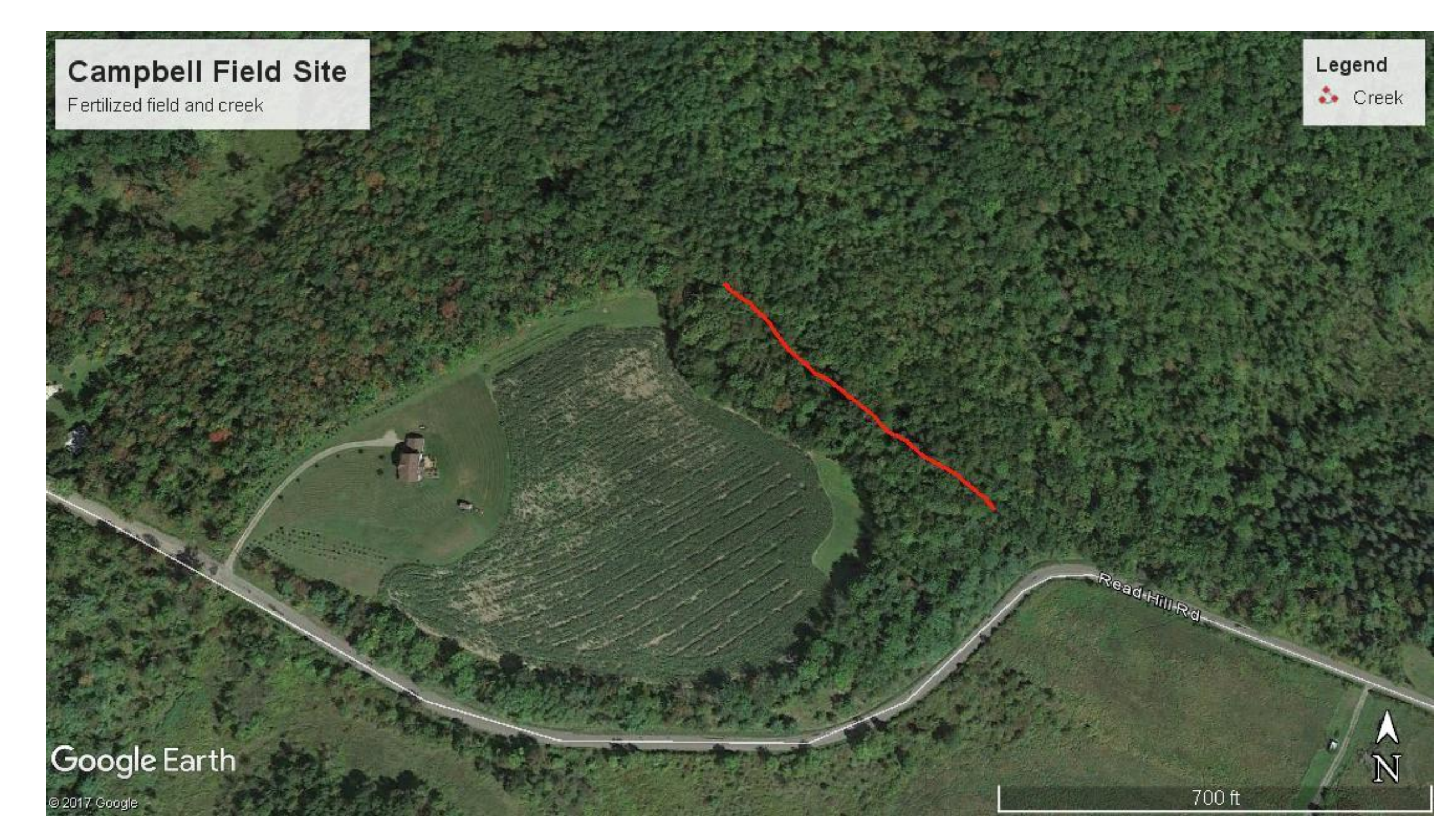

Figure 1: Map of Field of Study in Campbell, New York. (Google Earth)

\section{Methods}

6 soil moisture collectors (Soil Moisture Corp. Model 1900L) were installed on the edge of the agricultural field.

The collectors were installed in pairs at each location. One collector was installed to sample moisture at $20 \mathrm{~cm}$ depth and the other at $40 \mathrm{~cm}$ depth.

In the small stream within the ravine, a metal pipe was inserted in the stream bed to collect groundwater flowing into the stream. Surface water and

groundwater samples were collected from the same location.

A funnel and bottle precipitation collector were also installed to measure and collect precipitation falling on the agricultural field.

Samples of soil moisture, groundwater, surface water, and precipitation were collected every 2 weeks from May 2017 through December 2017. Samples were analyzed tor nitrates, phosphates, and sulfates us

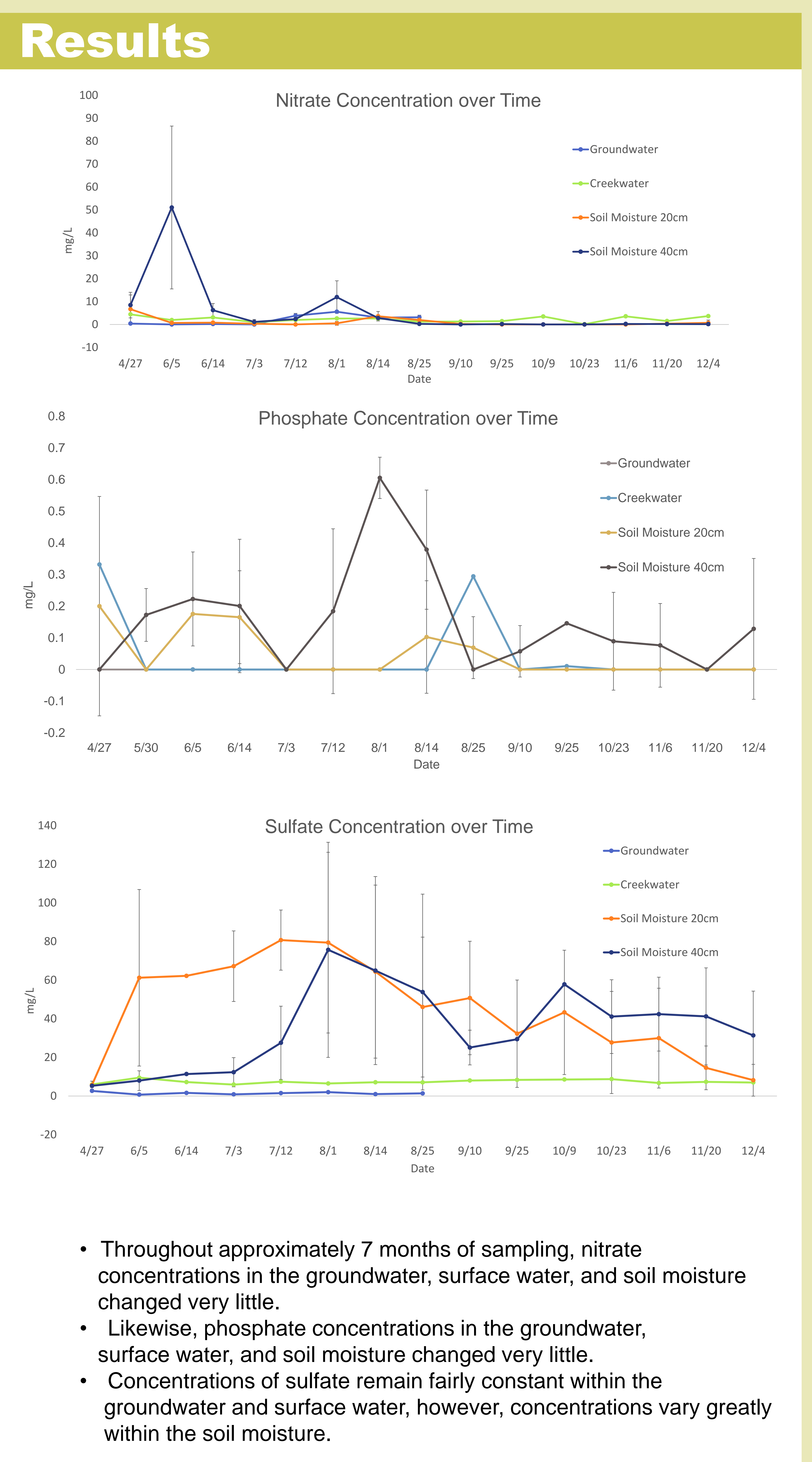

\section{Díscussion}

Nitrates and phosphates from fertilizer application peaked in the early spring the summer and into early fall, both nitrate and fhosphate concentration decreased and remained at considerably low levels.

The timothy and alfalfa that were planted in the study field readily took up the nitrates and phosphates from the fertilizer that was applied. As a result,

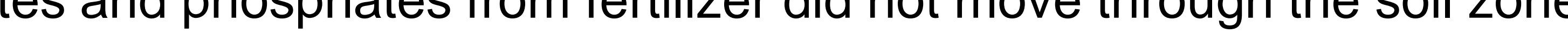
and end up in the groundwater or creek water.

Sulfates from fertilizer application peaked in the $20 \mathrm{~cm}$ depth soil moisture in late spring, early summer (late June-early July). Sulfates then peaked again in the $40 \mathrm{c}$ deph soll molsture in late sundy). (Augus) while phe sullates in month to move $20 \mathrm{~cm}$ in depth.

Sulfates from fertilizer application in the field of study were not readily taken up by the timethy and alfalfa. Instead, sulfates moved down through the soil moisture.

This suggests that sulfates from fertilizer application could in fact move down

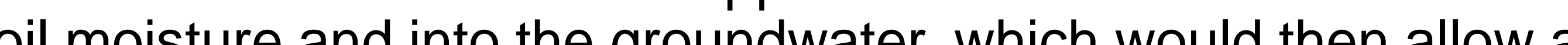
pathway of travel into the creek water.
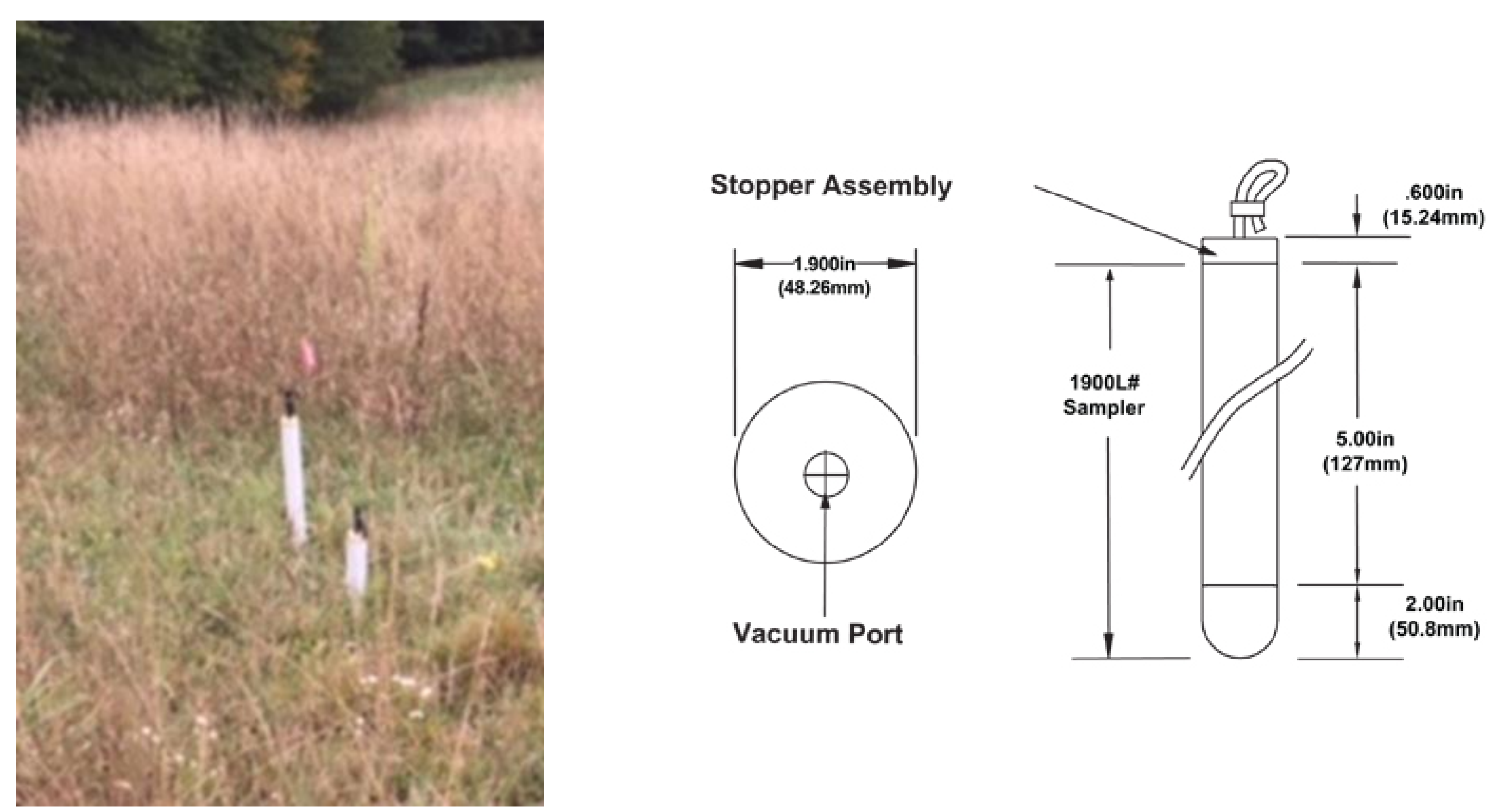

Figure 2: Soil Moisture collectors used in Campbell Field Site (Soil Moisture Corp. Model 1900L).

\section{Acknowledgements}

Thank you to my advisor Michele Hluchy for guiding me through this project and offering tremendous advice

Thank you to Nicole Munkwitz and Frederic Beaudry for running water samples in my absence over the summer and for offering tremendous advice

Thank you to my dad, Michael Siebert, for assisting in my collection of water

Thank you to Alfred University and the ARGUS (Alfred Research Grants for Underter for funding a large portion of my project

Galloway, J. N. J. W. Erisman, S. P. Seitzininer, R. W. Howarth, E. B. Cowling and B. J. Cosbby. 2003. The
Nitrogen Cascade. Bioscience, 53:341-356. Kivi, S. T. and R. T. Bailey. 2017 . Modeling sulfur cycling and sulfate reactive transport in an agricultural
groundwater system. Agricultural Water Management 185:78-92. Muiling, Z., S. Yuhong L. Yukun, Q. Fang, . L. Liqiao, L. Wen-Tso, D. Zhenyu and L.E Erchao. 2016. Response of
gut microbiota to salinity change in two euryhaline aquatic animals with reverse salinity preference. Aquaculture
454:72-80. 